\title{
A Scientist-Practitioner Perspective of the Internship Match Imbalance: The Stairway to Competence
}

\author{
Frank L. Collins, Jr. and \\ Jennifer L. Callahan \\ University of North Texas
}

\author{
Elizabeth A. Klonoff \\ San Diego State University/University of \\ California, San Diego
}

\begin{abstract}
This paper focuses on the supply and demand imbalance from a scientist-practitioner perspective, emphasizing competency development. A conceptual framework, the Stairway Model, illustrates the basic steps leading to emerging professional competence and stimulates research leading to thoughtful solutions to the internship match imbalance. Three immediate recommendations are offered. Doctoral programs should be (a) held accountable for their match rates, and (b) required to publicly disclose program and national match rates. Third, research must be conducted to determine factors that influence match rate and competency development. Concerns with other commonly proposed solutions are also discussed.
\end{abstract}

Keywords: competency, professional training, scientist-practioner training

As is clear from earlier papers in this series, for many years there have been discussions of solutions to the internship imbalance that ranged from enhancing the number of internship slots to serious consideration given to the need to reduce the number of students in professional psychology programs. More recently, discussions of alternative internship models, such as the half-time internship, the unfunded internship, or an internship designed primarily by the doctoral program (Emmons, Kenkel, Newman, Perl, \& Mangione, 2006) have received considerable attention. Although solutions to the internship match imbalance are needed, these solutions must be linked both to the purpose of the internship and to a clear understanding of what exactly the "prob-

Frank L. Collins, Jr. and Jennifer L. Callahan, Department of Psychology, University of North Texas; Elizabeth A. Klonoff, Department of Psychology, San Diego State University.

The perspective presented here is influenced by many other individuals, too numerous to mention here. However, the authors wish to gratefully appreciate discussions with Directors of Clinical Training from programs that are members of the Council of Directors of Clinical Psychology (CUDCP) and comments from the CUDCP Board on earlier drafts of this article.

CORRESPONDENCE CONCERNING THIS ARTICLE should be addressed to Frank L Collins, Director, Clinical Health Psychology Program, Department of Psychology, University of North Texas, 1611 W. Mulberry, Terrill Hall, Room 351, P.O. Box 311280 , Denton, TX 76203-1280. E-mail: frankcollinsphd@aol.com lem" is. The position taken in this paper is that the internship program is a critical step in the "Stairway to Competency" for professional psychology. The problem that should be of concern is not that many students do not match with their preferred internship slot; rather, the focus should be on (a) methods for developing entry-level professional competence in our students and (b) the role that internship training and program/internship match plays in the development of such competencies. The purpose of this paper is to describe a conceptual model of the supply and demand problem that may lead to solutions that are more thoughtful. Recommendations will be made regarding the need to identify programs that are not providing those experiences necessary for a successful match and to use these data to help programs enhance their outcomes.

\section{A Scientist-Practitioner Perspective on Internship Training}

Successful completion of an internship is a defining feature of doctoral education in professional psychology. This requirement is embedded in accreditation standards (Committee on Accreditation, 2008; Guidelines and Principles, Doctoral Programs, Domain A.4) and, for most trainees, this year long professional experience is the capstone experience of training that serves to launch the subsequent professional career. 
Although internship is only one-step along the stairway to entry-level professional competence, the internship, like the doctoral program one attended, is a major part of one's professional pedigree.

Although the specific internship experience varies by site and trainee, the Gainesville Conference on Internship Training reached a general agreement that the purpose of the internship is as follows:

\footnotetext{
"... to provide a systematic program of supervised, applied psychological training which extends and is consistent with the prior research, didactic, and applied experience of graduate education and training. Internship training will provide for the integration of scientific, professional, and ethical knowledge, attitudes, and basic skills to professional practice. The internship continues to provide for the professional socialization and development of professional identity. The person who completes the internship training is an individual who has demonstrated the capability to function autonomously and responsibly as a practicing psychologist" (Belar et al., 1987, pp. 4, italics added).
}

Thus, although the actual internship itself may vary in terms of populations served, theoretical models, supervisory styles, and other variables, all internship programs serve to facilitate the development of entry-level professional competencies. Postdoctoral experiences may continue to shape specialty professional competencies facilitating specialized careers in research, practice, and/or administrative settings; however, all graduates from doctoral psychology programs should have similar broad and general competencies (Committee on Accreditation, 2008), and these competencies should be sufficient for entry-level practice.

Clearly, these professional competencies do not suddenly emerge upon attaining the doctoral degree. Rather, competency emerges via a developmental framework (Kaslow et al., 2004). Trainee characteristics, many present before graduate training, combined with the sequence of training that occurs within the doctoral and internship programs results in entry-level professional competencies. Just as there are specific competencies that enhance the likelihood of a student being selected for graduate training (Appleby, Keenan, \& Mauer, 1999; Landrum, Jeglum, \& Cashin, 1994), it is probable that there are specific competencies that enhance the chance that a doctoral student will match at a particular internship site.

To better understand the developmental unfolding of professional competencies and their rela- tionship to internship training, it is imperative that psychology focus on these factors and not be distracted by the mere attainment of an internship match as a pseudofinal goal. The internship is a critical step in developing the minimum necessary competencies, but it is only one step.

Specifically, the authors of this paper have drawn inspiration from Paul's (1969) discussion of needed directions for psychotherapy research in formulating a conceptualization of directions for training research and have concluded that there is a need to identify what training experiences, under which set of circumstances, are most effective in developing competencies within a particular intern with specific goals and via what processes. The resultant Stairway Model is illustrated in Figure 1, with the internship match reflected by the step from the Doctoral Program to the Internship Training Year.

\section{The Stairway Model}

As evident in Figure 1, the elements that eventually lead to entry-level professional competence are present before admission into the doctoral program and shaped by training opportunities available in the doctoral program and internship site. The model focuses on three major steps: Trainee Characteristics, Doctoral Program Opportunities, and the Internship Year. Each step builds on the previous foundations and influences the eventual entry-level competencies of the emerging professional.

\section{Trainee Characteristics}

The foundation for competency development begins with preexisting Personal Aspects of the trainee (Association of Directors of Psychology Training Clinics [ADPTC], 2005), including demographic and personality characteristics as well as early educational experiences which impact the trainee's ability to benefit from training. Some characteristics are likely to be more important than others, and some more or less malleable by training; research is needed to identify which characteristics are critical for developing professional competencies. The second characteristic focuses on the Goals and Expectations that trainees possess. These differ from personal characteristics in that there is a strong likelihood that they will change to some 




Figure 1. Stairway model.

extent because of specific educational experiences. These trainee characteristics influence each other as well as influence acceptance to, and success in, doctoral training (American Psychological Association [APA], 2007).

\section{Doctoral Program Opportunities}

The next step toward competency development is the Doctoral Program. Three components have been identified that appear critical for preparing students to benefit from different types of internships. These are characterized as Experiences (e.g., practicum, coursework, and research), Circumstances (e.g., popula- tions that the trainee is exposed to and settings in which training occurs), and Processes (e.g., mentorship and/or supervision received) (Committee on Accreditation, 2008). Although the Stairway Model does not prescribe specific experiences, circumstances or processes critical for the trainee to move on to the next step, by identifying probable components, the model identifies the need to develop methods for evaluating which experiences, circumstances, and processes are most useful in helping students identify and secure placement in an internship program that will continue to facilitate the development of entrylevel professional competencies. 


\section{Internship Training Year}

Movement up the stairway to the internship year represents that the trainee has matched. Although the focus of this paper is on the internship match imbalance, it is important to emphasize what happens during the internship year, or else one might be distracted into thinking that matching for an internship alone is synonymous to entry-level professional competence. The model presented in Figure 1 does not label the components of the internship; however, the authors conceptualize internship has having similar components as doctoral programs, although at a more advanced level. That is, internships provide particular experiences (primarily experiential rather than didactic) under certain circumstances (primarily rotations), using a range of processes (primarily mentored supervision). Different internships are likely to be more or less effective in helping trainees develop professional competencies, in part, because of differing doctoral program preparation and individual trainee characteristics.

\section{Emerging Professional}

At this point, the individual is meant to be ready to engage in more self-directed learning and professional roles. However, it should not be assumed that a given individual who has completed the doctoral degree and internship possesses the minimum necessary professional competencies to function at this level. For excellent reviews of major domains of expected competencies, including how they developmentally unfold, see the 2004 special issue of the Journal of Clinical Psychology on competencies (Collins, Kaslow, \& Illfelder-Kaye, 2004).

Despite the fact that matching to an internship is not a goal in and of itself, the fact that significant numbers of students are unable to complete the internship portion of their education in a timely manner is nonetheless a problem for the field as a whole. As a result, a number of solutions have been suggested. What follows are some of the suggestions many that have been stimulated by discussions within Council of Directors of Clinical Psychology (CUDCP).
Solutions to the Internship Imbalance

\section{Hold Doctoral Programs Accountable for the Match Rates of Their Program}

The internship year is the final step before entry-level practice. It serves both a training and gatekeeper function. Training functions include providing students with additional, sometimes focused, experiences with particular populations in various settings. These experiences are provided under professional supervision with the internship staff serving as mentors and professional role models for the trainee. These components of internship training represent more in depth experiences of the types present in the doctoral program and, as such, serve to enhance already existing competencies, or to train emerging competencies that derive from existing ones. Thus, any plan to address the problem that students face when leaving the doctoral program for internship training must address preparation in the graduate program.

In 1970, a famous quote by Walter Kelly appeared on Earth Day posters (Kelly, 1982), "We have met the enemy, and he is us" (p. 224). This sentiment is not unfamiliar to those in the training community currently dealing with issues related to supply and demand. To a large degree, this is a self-made problem. Had psychology not been populated with talented instructors who motivated the equally talented high school and undergraduate students to consider, and then to pursue, graduate education in professional psychology, these discussions would not be needed. However, the fact is there are currently more students who want to become psychologists and who apply for admission than can be accommodated in academic training programs (Norcross, Kohout, \& Wicherski, 2005). Likewise, there are more individuals who finish the academic requirements of their training than are able to match to internships (Association of Psychology Postdoctoral Internship Centers [APPIC], 2006b; 2007).

Although it is clear that there are more individuals who apply for internships than the number of internship slots available, there also is a great deal of variability in terms of programs providing (or failing to provide) the foundation training that make their students competitive. The overall match rates for the past 3 years (2005, 2006, and 2007) were 79\%, 77\%, and 
75\%, respectively (APPIC, 2005, 2006a, 2007), but a review of the aggregated data provided by APPIC on program match rates for the years 2000 to 2006 reveals that 96 institutions had at least one program (i.e., clinical, counseling, school, combined, or other) with an overall match rate below $70 \%$; 38 of these institutions had at least one program with a match rate below 50\% (APPIC, 2006b). A total of 1,378 students were from those programs with match rates of less than 50\%; the proportion of these students who were ill prepared for the internship experience when they applied is currently unknown.

To what degree does the field find it acceptable that a program, in over 6 years of training students, is unable to get at least half of its students matched to an internship? It is not acceptable to suggest that resolution of the internship imbalance problem is primarily the responsibility of APPIC to simply develop "more" intern slots or internship sites; much of the responsibility rests with the doctoral programs to ensure that the students who are entering the match are adequately prepared to function at the intern level. The APPIC (2006b) data also demonstrate that there are a number of programs that consistently match at $90 \%$ or better; to do so, these programs must be producing high quality students with whom the internship sites are pleased, or else the match rate for these programs would no doubt be reduced over time. Given that completion of an internship is a required part of doctoral education in accredited programs (Guidelines and Principles, Doctoral Programs, Domain A.4; Committee on Accreditation, 2008), the success of a program in having students obtain internships should be one of the student learning outcomes evaluated by the newly formed Commission on Accreditation (CoA). Specifically the CoA must develop and adopt an implementing regulation (IR) with respect to Domain B (Program Philosophy, Objectives, and Curriculum Plan) Point 2 (The program specifies education and training objectives in terms of the competencies expected of its graduates). Rather than an individual student's learning outcome and objective, this IR should define appropriate outcomes for the program with respect to internship placements. Any program that is consistently unable to place its students in internship sites (e.g., repeatedly has a match rate lower than the national match rates) should be required to develop a clear remediation plan, with explicit goals and procedures to improve the program's match rate.

Including success in internship placement as part of the criteria for accrediting doctoral programs is consistent with the general philosophy that has characterized graduate education in psychology: education must be internally consistent with the program's model (Committee on Accreditation, 2008). Thus, even with increased accountability, programs would retain the ability to deal with their lower match rates in the manner that is most appropriate to their program model. Using the Stairway model, the program might be able to identify unique methods for improving their match rates, such as reducing the size of their classes (Experiences); being more selective in the students they admit (Trainee Characteristics); better preparing students before they apply for internship (Experiences, Circumstances, and/or Processes); and other similar strategies.

\section{Require Public Disclosure of Internship Match Rates}

Whereas the new disclosure requirements required by the $\mathrm{CoA}$ for accredited programs are helpful (CUDCP implemented similar disclosure requirements for its member programs more than 5 years ago), merely placing these data on individual program Web pages or in written materials is not sufficient. Programs can vary in the speed with which they respond to these new requirements, the degree to which these data are easily and quickly available to potential consumers/students, and so forth. Specific instructions for clear placement of this data and monitoring of timely updates are needed.

Further, it is recommended that, in addition to programs being required to provide public disclosure of the program's data, data that are provided must be done within a context of national norms. Specifically, programs should report their match rates over several consecutive years in addition to the corresponding nation wide match rates. If their current match rate falls below the national average, the program should specify the interventions enacted to improve internship match rates.

Likewise, it would seem reasonable that at least 3 year's worth of match data (obtained from APPIC if at all possible) be prominently placed in the description of each program in the 
APA Guide to Graduate Programs, the Insider's Guide to Graduate Programs in Psychology, and other such guides for students applying to graduate school. In addition to the match rate data, a brief consistent statement, underscoring that the completion of an internship is a requirement for obtaining the doctoral degree from an APA accredited program and that prospective students should carefully consider the success of students from any given program in obtaining an internship, should accompany these data in each program's listing. Such information would allow prospective students to better evaluate a potential graduate program, particularly if the eventual goal of the student is to engage in professional practice; programs that do not facilitate students completing all of the requirements necessary for licensure (e.g., internship) may end up being less attractive to these kinds of students.

\section{Develop a Systematic Research Program to Determine Factors That Influence Match Rate and Competency Development}

The Stairway Model provides a framework within which research can be conducted to determine the factors that influence acceptance into various kinds of graduate programs (movement from undergraduate education to graduate training), match rates (movement from the Doctoral Program to the Internship Training Year), and eventual entry level competency (movement from the Internship Training Year to Emerging Professional). Although this goal is the most challenging, it has the potential to provide the greatest benefit to the field.

One of the problems of focusing merely on the match statistics is that it ignores the real purpose of internship. Securing an internship is not the "real" goal of training, but rather merely a step in the process. The goal is to develop those competencies necessary to function as a professional psychologist. As such, trainee characteristics should lead students to different doctoral programs; different doctoral programs should expose their students to unique experiences, circumstances, and processes that lead to different internship programs; and, finally, different internship programs will result in differing competencies.

All doctoral trained psychologists are expected to have broad and general training (Committee on Accreditation, 2008), and there is an expectation that each of these paths result in basic competencies expected of all professional psychologists. However, as pointed out earlier in this article, the real question that needs to be asked is:

What training experiences, under which set of circumstances, are most effective in developing competencies within a particular intern with specific goals and via what processes.

Merely knowing that a student matched does not guarantee that the internship where he or she matched will provide that specific intern with the needed experiences to develop the competencies necessary for entry level practice.

Although much work is currently being done to identify these basic general competencies, it is imperative that data be available to determine the relationship between particular trainee characteristics, and those experiences, circumstances and processes that occur in doctoral programs and internship training that result in professional competence. The Stairway Model provides guidance as to potential aspects that need to be investigated, and research is needed to evaluate these components.

\section{Concerns About Some of the Other Proposed Solutions}

The field needs to be cautious when considering alternatives to the traditional sequence of training leading to the development of professional competence least we build a stairway with weak steps, resulting in trainees never developing needed entry-level competency. Some have suggested that the internship-training year is a barrier to some students that should be addressed by replacing this year-long experience with alternative, part-time experiences, encouraging the development of internship sites even if those sites cannot pay interns, and having doctoral programs work to develop their own "internship" sites.

Although it is possible that traditional models of internship training can be improved, most of the reasons given for developing alternative models are based on the fact that many students from some programs and/or from programs using some kinds of training models (Neimeyer, Rice, \& Keilin, 2007) do not find a match using the existing APPIC systems. We feel that these proposed alternatives, whereas having potential 
for reducing the sheer number of unmatched individuals, must be evaluated within a context that gives careful attention to the purpose of internship training to ensure that trainees who receive such alternative training develop and demonstrate attainment of the same or equivalent expected critical competencies needed for professional practice.

The most widely discussed alternative model is the "half-time" internship model (Peterson \& Ober, 2006). To some extent, half-time internships are not new, and both APA accreditation guidelines and most state licensure laws allow for the 2,000-hr internship experience to be completed in either 1 year or over 2 years. Although this method for internship has not been widely accepted by the field in general (Emmons et al., 2006), more than $75 \%$ of internship sites listed by the California Psychology Internship Council in 2004 through 2005 were half-time positions (Law, 2005). The growth of the "half-time" model in California led to a training conference held in Berkeley in March 2005 designed to identify the need for, and obstacles to, this alternative to the traditional internship.

The primary rationale for development of these alternative models is that many students, particularly students who are geographically bound, struggle to obtain a match with traditional fulltime internships (Peterson \& Ober, 2006). Similarly, it is argued that students in psychology training programs may be less mobile today than in the past, although little data are provided to support this argument. However, most half-time internships do not provide stipend support, few are APA accredited or meet APPIC minimal standards, and most are located in California (Emmons et al., 2006), which aids only those students geographically constrained to that state. Although these sites meet licensure requirements for the State of California, failure of these programs to meet the minimal standards identified by APA Accreditation is of concern.

Three major concerns that need to be addressed when considering alternative models of internship were identified during the Half-Time Internship Conference (Law, 2005). These concerns were (a) sequence and regulation, (b) funding and advocacy, and (c) quality assurance. All of these seem to link to our broad conceptualization of the purpose and function of internship training outlined above. With respect to sequence and regulation, the confer- ence developed a guide for programs to use to assist with the development of consortia and to encourage more dialogue, and suggested that perhaps a national conference to reexamine the interface between internships and doctoral programs was in order. We agree that more dialogue regarding the interface between internships and doctoral programs is needed, but it is not clear that there is a need for academic programs to run their own internship sites, nor is it clear that this is even desirable. There is at least some degree of external evaluation in the existing system whereby applicants who do not have the necessary competency for internship are not admitted. Internships run by the doctoral program would be under great pressure to admit students and work on remedial strategies that would detract from the critical learning experiences that are expected from internship. Even worse would be the situation where students apply for the match, and only those who do not match somewhere else are placed in the doctoral-program administered internship site; given the concerns raised earlier about the degree to which programs where students consistently fail to match do or do not do a good job of preparing students for internships, giving those same programs the additional responsibility of now overseeing an internship seems to be a high risk situation.

Funding and advocacy refers to the need to reify the importance of the services provided by individuals in training It seems somewhat hypocritical as Peterson and Ober (2006) have suggested, to argue that students cannot afford to take a full-time internship, but can afford to work for free 20 hours per week across 2 years. For this alternative model to be viable funding is inherently necessary and there must be recognition of the value of services provided by trainees. This recognition is important to the trainees as well; they need to see that they are doing more than merely meeting some arbitrary program requirement, but rather are proving a useful and valuable service, one that merits they be paid to provide.

Finally, there is a need to ensure that the competencies expected of trainees while completing an internship are not compromised. These quality assurance aspects are critical. The field must differentiate practicum competencies from internship competencies (ADPTC, 2005). It is not sufficient to merely have stu- 
dents in a program complete a 20 hour per week placement for 2 years and label it as internship. Internship training must be the next step in professional training and not merely 1 or 2 years more year of doctoral training. The need to clearly discriminate between what is labeled a "practicum" and what is labeled an "internship," particularly when both would be administered by the doctoral program, is a major consideration when thinking about quality assurance. In addition, the need to demonstrate that the training in these contexts is at least as good as, if not better, than the training offered in traditional internship sites is another quality assurance issue.

\section{Summary}

More students currently apply for internship than the number of available slots. There is a need for individuals in the training community to begin to identify a solution that ensures that well trained students, who are ready for internship, will be matched in accredited sites. The present paper provides a developmental model of the sequence of training leading to the Emerging Professional. The internship is a critical step in this model and solutions to the internship match must look at the reasons why the vast majority of programs have match rates above the national average while a few programs are failing at alarming rates.

The solution to the problem must remain focused on finding the best match for each student wherein internship can serve to strengthen competencies being developed during doctoral training, resulting in a strong entry-level professional. Any alternative that merely finds a way for every intern to be placed in an internship just to meet program requirement rather than to foster competency development, should not be considered. The Stairway Model allows for programmatic research to identify those factors that will be most effective for developing competencies for each applicant and allows programs to make changes to enhance match rates for their students.

\section{References}

American Psychological Association. (2007). Getting in: A step-by-step plan for gaining admission to graduate school in psychology (2nd ed.). Washington, DC: Author.

American Psychological Association. (2008). Guidelines and principles for accreditation of programs in professional psychology. Washington, DC: Author.

Appleby, D., Keenan, J., \& Mauer, B. (1999). Applicant characteristics valued by graduate programs in psychology. Eye on Psi Chi, 3, 39.

Association of Directors of Psychology Training Clinics. (2005). Report on practicum competencies. Retrieved May 15, 2007, from http://www.adptc.org/ public_files/CCTCPracticumCompetenciesChart RevFeb2005.doc.

Association of Psychology Postdoctoral Internship Centers. (2005). APPIC match statistics: Match report from the APPIC board of directors. Retrieved September 3, 2007, from http://www.appic.org/ match/5_2_2_1_7_match_about_statistics_general_ 2005.html.

Association of Psychology Postdoctoral Internship Centers. (2006a). APPIC match statistics: Match report from the APPIC board of directors. Retrieved September 3, 2007, from http://www.appic. org/match/5_2_2_1_8_match_about_statistics_ general_2006.html.

Association of Psychology Postdoctoral Internship Centers. (2006b). APPIC match 2000-2006: Match rates by doctoral program. Retrieved July 14, 2007, from http://www.appic.org/downloads/APPIC_ Match_2000-06_by_Univ.pdf.

Association of Psychology Postdoctoral Internship Centers. (2007). APPIC match statistics: Match report from the APPIC board of directors. Retrieved July 14, 2007, from http://www.appic.org/match/ 5_2_2_1_9_match_about_statistics_general_2007. html.

Belar, C. D., Bieliauskas, L. A., Larsen, K. G., Mench, I. N., Poey, K., \& Roehlke, H. J. (Eds.). (1987). Proceedings of the national conference on internship training. Baton Rouge, LA: Land and Land Printers.

Collins, F. L., Jr., Kaslow, N. J., \& Illfelder-Kaye, J. (Eds.). (2004). Competencies conference: Future directions in education and credentialing in professional psychology [Special issue]. Journal of Clinical Psychology, 60(7).

Committee on Accreditation. (2008). Guidelines and principles for accreditation of programs in professional psychology. Washington, DC: American Psychological Association.

Emmons, L., Kenkel, M. B., Newman, G. H., Perl, R., \& Mangione, L. (2006). A framework for halftime internship in psychology. Professional Psychology: Research and Practice, 37, 643-650.

Kaslow, N. J., Borden, K. A., Collins, F. L., Forrest, L., Illfelder-Kaye, J., Nelson, P. D., \& Rallo, J. S. 
(2004). Competencies conference: Future directions in education and credentialing in professional psychology. Journal of Clinical Psychology, 60, 699-712.

Kelly, W., \& Crouch, B., Jr. (Eds.). (1982). The best of Pogo. New York: Simon \& Schuster.

Landrum, R. E., Jeglum, E. B., \& Cashin, J. R. (1994). The decision-making processes of graduate admissions committees in psychology. Journal of Social Behavior and Personality, 9, 239-248.

Law, B. M. (2005). Considering the half-time internship. Monitor on Psychology, 36, 28.

Neimeyer, G. J., Rice, K. G., \& Keilin, G. (2007). Does the model matter? The relationship between science-practice emphasis in clinical psy- chology programs and the internship match. Training and Education in Professional Psychology, 1, 153-162.

Norcross, J. C., Kohout, J. L., \& Wicherski, M. (2005). Graduate study in psychology: 1971-2004. American Psychologist, 60, 959-975.

Paul, G. L. (1969). Behavior modification research: Design and tactics. In C. M. Franks (Ed.), Behavior therapy: Appraisal and status (pp. 29-62). New York: McGraw-Hill.

Peterson, R. L., \& Ober, M. D. (2006). Reconsidering assumptions: Half-time internships in their historical context. Professional Psychology: Research and Practice, 37, 635-642. 